\title{
Televisão digital interativa: expectativas de uso cultural e educativo
}

Marcelo Sacrini

Jornalista. Especialista em Informática em Educação. Mestrando em Educação pela Faculdade de Educação da Universidade de São Paulo (FEUSP).

E-mail: sacrini@gmail.com

A televisão é usualmente considerada o principal meio de comunicação e fonte de informação, entretenimento e consumo da maior parte das populações de países em todo o mundo. A hegemonia do aparelho se consolidou aos poucos desde o seu surgimento, em meados do século XX, mas principalmente após o acelerado desenvolvimento tecnológico que trouxe portabilidade aos equipamentos e permitiu a elaboração de programas mais próximos de uma suposta verdade explícita somente nas ruas, longe dos estúdios. Seu predomínio enquanto meio de comunicação de massa se firmou ainda mais com a invenção do videoteipe, a disseminação das locadoras de filmes nos anos 1980 e a explosão do uso dos videocassetes, que se configurariam importantes instrumentos para a segmentação eficaz dos conteúdos, ao possibilitar a gravação e distribuição de filmes e programas conforme o interesse do telespectador.

Um pouco depois do surgimento da televisão, e com grande vigor a partir dos anos 1990 até a atualidade, os computadores foram inventados e vêm se sofisticando cada vez mais, consolidando-se como ferramenta de interação entre os indivíduos conectados nas redes locais ou mundiais de comunicação digital e se tornando o aparato-chave de uma sociedade dita informacional. Essa nova sociedade, apoiada nas tecnologias da inteligência e viabilizada por uma configuração social estruturada pelo predomínio da informação digitalizada e mercantilizável, é objeto de estudos vastamente elaborados por pensadores como Lyotard ${ }^{1}$, Castells² e Lévy³.

A principal característica da televisão convencional analógica diz respeito ao tipo de difusão do conteúdo. Normalmente, um conteúdo televisivo é criado para atender um público-alvo bastante diverso e abrangente. Embora a segmentação já seja admissível em sistemas mais avançados de transmissão, em sua história essa possibilidade foi sempre muito restrita.

O computador conectado em rede, por sua vez, permite uma personalização cada vez mais eficiente do conteúdo buscado pelo usuário, com a recuperação de informações específicas de acordo com seu interesse. Os sistemas computacionais e a comunicação pela internet podem organizar para o leitor dados

1. LYOTARD, Jean-François. A condição pósmoderna. 7. ed. Rio de Janeiro: José Olympio, 2002.

2. CASTELLS, Manuel. A sociedade em rede. 8. ed. rev. ampl. São Paulo: Paz e Terra, 2005. v. I.

3. LÉVY, Pierre. As tecnologias da inteligência: o futuro do pensamento na era da informática. Rio de Janeiro: Editora 34, 2000. 
absolutamente individualizados, conforme seus hábitos de navegação, que são registrados por marcadores de acesso (cookies), por exemplo, ou com o uso de dispositivos agregadores de conteúdos, como o Rich Site Summary (RSS), um formato-padrão para o compartilhamento de conteúdo web.

Já implementada e em uso em alguns países desenvolvidos, é certa a convergência tecnológica parcial ou integral desses dois recursos também no Brasil, configurando um novo equipamento que integra sistemas digitalizados de produção e envio de conteúdos audiovisuais interativos - numa interface bastante consagrada - a algumas possibilidades de conexão em rede, com o uso de um canal de retorno, o que vem sendo apresentado como a televisão digital interativa.

Trata-se da televisão como a conhecemos com os processos de produção, encapsulamento, envio e recepção de sinais totalmente digitalizados. Dependendo do sistema adotado, podem ser incorporadas algumas possibilidades de interação do usuário com o sistema, com o conteúdo, entre conteúdos, ou com seus provedores. Assim, a disseminação de uma televisão que é digital, e que pode ser interativa, deve transformar o meio que lhe deu origem, convertendose em um novo ambiente de comunicação e interação que soma características e possibilidades de diversos aparatos preexistentes.

Uma discussão que acompanha a existência dos dois equipamentos, televisão e computador, está relacionada com a utilização desses instrumentos tecnológicos no contexto educativo pelas sociedades que exploram seus recursos. $\mathrm{O}$ presente texto pretende acoplar à discussão já em andamento sobre o uso dos computadores nos procedimentos pedagógicos algumas expectativas quanto à apropriação e uso crítico da televisão digital nos processos de aquisição e construção do conhecimento.

\section{METODOLOGIA}

A partir da pesquisa documental ${ }^{4}$, o artigo recupera e agrupa algumas informações sobre as aplicações plausíveis ao uso da televisão digital nos processos educativos: seu aproveitamento enquanto espaço para veiculação de programas culturais interativos e de entretenimento educativo com a apropriada migração das emissoras para o novo sistema; sua potencialidade como repositório de programas para acesso on-demand (sob demanda), que poderão ser produzidos e distribuídos por provedores de conteúdos; sua utilização como ponta de uma rede de intercâmbio para as televisões universitárias; a apresentação da experiência preliminar da TV Escola Digital Interativa; a proposta do Serviço de Apoio ao Professor em Sala de Aula - SAPSA, além do exemplo de uma aplicação específica de conteúdo, com a apresentação do documentário digital interativo. Antes,

4. LAKATOS Eva Maria; MARCONI, Marina de Andrade. Metodologia do trabalho científico 6. ed. rev. ampl. São Paulo: Atlas, 2001. mostra os modelos tecnológicos que efetivamente participaram do processo de escolha recentemente desenvolvido no Brasil, até a decisão, ocorrida em junho de 2006, do padrão tecnológico definido para ser implementado no País. 
Não serão escopo deste estudo as aplicações relacionadas ao ensino a distância, exatamente por compreender que a importância da utilização da televisão digital nesse contexto particular do processo educativo requer uma pesquisa específica sobre as reais possibilidades de uso. Servirá, porém, para subsidiar os trabalhos futuros já que identifica algumas potencialidades para o uso do aparato com esse objetivo.

\section{OS MODELOS TECNOLÓGICOS ENVOLVIDOS}

A grande discussão que antecedeu a definição do padrão tecnológico para a televisão digital brasileira trouxe consigo aspectos que extrapolaram a simples escolha de um modelo; dentre tantos motivos, principalmente por terem relação com os consideráveis volumes de investimento a serem aplicados nos próximos anos na direção do padrão eleito. Sendo assim, seria natural esperar que indústria, empresas de comunicação e de tecnologia, assim como grupos econômicos de diversos segmentos participassem e interferissem de maneira contundente na decisão do governo; como também seria razoável presumir que tal definição resultaria da ponderação entre os pareceres técnicos gerados e a força dessas interferências. Entretanto, vale lembrar que, logo após o anúncio da tecnologia escolhida, muito se discutiu na mídia especializada sobre um irrelevante compromisso do governo diante do parecer técnico apresentado pelas entidades de pesquisa, valorizando-se demasiadamente o peso político das pressões sofridas.

Apesar deste breve registro do momento da decisão, que em 2006 ainda vivemos, é importante salientar que o aspecto político desse processo não será objetivo nem objeto do presente estudo, pois merece uma análise contextual e conjuntural mais profunda dada a importância do assunto.

Independentemente da definição do modelo tecnológico escolhido para o País, a abordagem deste trabalho está voltada mais às possibilidades de utilização do aparato depois de definido e implementado do que para os pontos inerentes ao processo político-decisório, principalmente pelo foco nas aplicações no cenário educativo, pretendido aqui.

Ainda assim, considera-se importante um conhecimento, mesmo que pouco aprofundado, dos modelos existentes e que participaram do processo de seleção, já que cada um traz características peculiares que poderiam modificar o olhar sobre as possibilidades de sua utilização e sobre a elaboração dos conteúdos.

Três sistemas disputaram o aval oficial para serem adotados como base para o padrão brasileiro: o primeiro, de acordo com o padrão tecnológico norteamericano; o segundo, baseado no padrão europeu; e, o terceiro, conforme o padrão japonês. Havia também uma possibilidade de desenvolvimento de um sistema originalmente brasileiro, que pretendia incorporar características e qualidades dos três padrões apresentados anteriormente. Apesar de várias vezes cogitado, o padrão nacional foi descartado no decorrer das discussões. 
comunicação \& educação • Ano XI • Número 3 • set/dez 2006

5. BECKER, Valdecir: MONTEZ, Carlos. TV digital interativa: conceitos, desafios e perspectivas para o Brasil. Florianópolis: 12TV, 2004. p. 127-136.

6. CPqD - Fundação Centro de Pesquisa e Desenvolvimento em Telecomunicações. Modelo de implantação da TV digital no Brasil - Produto II: panorama mundial da implantação da tecnologia digital na transmissão terrestre de televisão, 2002. p. 32.
Becker e Montez ${ }^{5}$ apresentaram em seus trabalhos os principais modelos de televisão digital disponíveis, com destaque aos padrões já consolidados e mencionados antes, conforme brevemente descritos a seguir.

O modelo ATSC - Advanced Television Systems Committee funciona nos Estados Unidos desde 1998, e é também adotado pelo Canadá, Coréia do Sul e Taiwan. O sistema privilegia a alta qualidade de imagem (HDTV) e som (Dolby AC-3), características buscadas pelo mercado consumidor norte-americano. $\mathrm{O}$ meio de transmissão predominante é o sistema a cabo (pago), cuja infra-estrutura cobre cerca de $95 \%$ dos domicílios daquele país ${ }^{6}$.

O padrão europeu é conhecido como DVB - Digital Video Broadcasting e, além dos países da Europa, é usado na Austrália, Malásia, Índia, África do Sul e em Hong Kong, entre outros. A Inglaterra tem o sistema digital mais consolidado, em operação desde 1993, com difusão tanto a cabo como via satélite e terrestre. O foco de utilização desse padrão está voltado para a prestação de serviço com grande interatividade: serviços de internet, portais, provimento de conteúdos e serviços de telefonia. Apesar de o sistema ser pago, muitas vezes os equipamentos são subsidiados pelas operadoras de TV.

O Japão desenvolveu isoladamente o sistema ISDB - Integrated Services Digital Broadcasting em 1999, com o objetivo maior de privilegiar uma grande flexibilidade de operações e a utilização em suportes portáteis e móveis. A plataforma japonesa promete oferecer conteúdos em alta definição de imagem com serviços interativos, características dos dois sistemas apresentados antes, tanto em dispositivos fixos como móveis, o que o distingue como o modelo aparentemente mais flexível no que se refere às possibilidades de uso.

$\mathrm{O}$ governo brasileiro delegou ao $\mathrm{CPqD}$ - Fundação Centro de Pesquisa e Desenvolvimento em Telecomunicações a tarefa de elaborar alguns estudos tecnológicos para subsidiar a decisão sobre o modelo a ser adotado no País, o que poderia em tese envolver a escolha de um dos modelos já existentes ou o desenvolvimento de um padrão nacional próprio de televisão digital. Além desse trabalho, vários consórcios e conselhos foram agrupados pelo Ministério das Comunicações para desenvolver o debate público e apresentar os resultados das pesquisas desenvolvidas pelas instituições acadêmicas, coordenados pelo CPqD.

Conforme anunciado no Diário Oficial da União, de 30 de junho de 2006, o Decreto no 5.820, de 29 de junho de 2006, definiu o sistema japonês (ISDB-T - Integrated Services Digital Broadcasting Terrestrial) como base para o Sistema Brasileiro de Televisão Digital Terrestre - SBTVD-T.

\section{CAMINHOS OFICIAIS NA ESCOLHA DO MODELO}

O debate sobre a digitalização da televisão no Brasil vem sendo desenvolvido há mais de dez anos no País. Os primeiros testes dos sistemas tecnológicos existentes aconteceram no segundo mandato do presidente Fernando Henrique Cardoso, até 2002. A decisão, entretanto, foi postergada por aquele governo para o próximo presidente eleito, Luiz Inácio Lula da Silva. 
O significado dessa discussão, ainda em andamento mesmo depois da escolha do padrão tecnológico, tem relação direta com o valor dado ao meio de comunicação pela sociedade e à importância da televisão para pessoas de todas as classes socioculturais do País. Segundo o Ministério das Comunicações, o Brasil possui mais de 54 milhões de televisores em $87 \%$ dos lares brasileiros (1,4 TV/lar). Desses, $79 \%$ recebem a transmissão via radiodifusão terrestre, em sinal aberto, motivo pelo qual o governo se empenhou na definição de um padrão também aberto de televisão digital para o País ${ }^{7}$.

A institucionalização de uma televisão digital somente foi possível após a regulamentação do Fundo para o Desenvolvimento Tecnológico das Telecomunicações - Funttel, oficialmente estabelecida em 30 de janeiro de 2001, pelo Decreto no 3.737 assinado pelos então presidente, Fernando Henrique Cardoso, e ministro das Comunicações, Pimenta da Veiga. O Funttel, que depois financiou as pesquisas para o Sistema Brasileiro de Televisão Digital - SBTVD, na verdade já havia sido instituído em 2000, pela Lei federal no 10.052, de 28 de novembro daquele ano. Seu objetivo, basicamente, era viabilizar e estimular o processo de inovação tecnológica no Brasil no âmbito das telecomunicações ${ }^{8}$.

Um debate caloroso sobre a repercussão do modelo escolhido e tantos outros assuntos relacionados ao processo decisório para a televisão digital têm sido desenvolvidos sistematicamente por organizações não-governamentais e representantes da sociedade civil, e podem ser acompanhados pelos documentos publicados nos sites de instituições como o Fórum Nacional pela Democratização da Comunicação - FNDC (http://www.fndc.org.br/), o Projeto Brasil (http:// www.projetobr.com.br/), o Intervozes - Coletivo Brasil de Comunicação Social (http://www.intervozes.org.br/) e o Centro de Mídia Independente - CMI Brasil (http://www.midiaindependente.org/), além de tantas listas de debates, fóruns e blogs disponíveis na rede mundial de computadores.

\section{EXPECTATIVAS: USO CULTURAL E EDUCATIVO}

Toda experiência de uso de novos aparatos tecnológicos nos processos educativos de ensino e aprendizado gera sempre grandes expectativas quanto aos resultados prometidos, sem às vezes levar em conta as implicações que envolvem o uso desses recursos, não raramente subutilizados ou explorados de forma inadequada e pouco produtiva. Ainda assim, sabe-se que a aplicação das tecnologias digitais em rede, por exemplo, possibilita novas formas de produção e acesso a informações antes restritas, permitindo a construção do conhecimento num grau jamais visto.

Parte-se sempre do pressuposto de que a utilização de aparatos tecnológicos em sala de aula ou em momentos informais de apreensão de cultura pode promover melhoria nos processos cognitivos do indivíduo, ou serve de elemento diferencial que o motiva a se envolver com os conteúdos para a construção de algum conhecimento.

O mesmo fenômeno será novamente experimentado com o uso da televisão digital nesse contexto e, embora haja muitas expectativas, sabe-se que o emprego
7. <http://www.mc.gov $\mathrm{br} />$.

8. BRASIL. Ministério das Comunicações. FUNTTEL. Decreto n- 3.737 , de 30 de janeiro de 2001. 
comunicação \& educação • Ano XI • Número 3 • set/dez 2006

efetivo depende das possibilidades adensadas pela tecnologia somadas a uma adequada qualificação daquele que a utiliza, problema recorrente nessas questões.

O modelo de televisão digital escolhido pelo governo poderá integrar transmissão terrestre de sinais, satélite, telefonia fixa e internet em banda larga para tornar disponíveis aos usuários textos, imagens e som. Diferentemente do sistema original analógico, a televisão digital possibilita a transmissão de conteúdos complementares, guias didáticos e de orientação, tabelas, artigos, além de conteúdos que poderão ser enviados de volta ao provedor do serviço ou da programação - isso dependerá da existência de um canal de retorno, que envia sinais e dados para a solicitação e/ou agendamento de conteúdos extras e serviços. Uma opção bastante adequada, pela grande capilaridade de sua abrangência, seria utilizar a rede de telefonia fixa instalada no País, já que tem alcance em praticamente todo o território brasileiro.

Dentre as principais inovações trazidas pela televisão digital no contexto educativo, podemos esperar aquelas relacionadas com as aplicações multimídias e a conexão dos aparelhos entre si, por meio de protocolos específicos ou já utilizados na rede mundial de computadores. Esse potencial permitirá ao usuário interagir e intervir na produção dos conteúdos. Para os processos de ensino e aprendizado, irá significar um avanço sem precedentes no meio televisivo, pois poderá compor, num mesmo aparato, recursos e sistemas de informação que exploram determinados assuntos com uma capacidade de interação entre as partes desse sistema, essencial para alguma avaliação daquilo que foi apreendido.

Nesse sentido, a ferramenta possibilitará o exercício completo das atividades educativas por meio de recursos audiovisuais com o apelo das já consagradas transmissões televisivas, permitindo uma reconfiguração das formas de contato com o conhecimento a partir do oferecimento de "serviços para a teleducação que têm como eixo uma pedagogia comunicacional de apoio ao professor em sala de aula, apoio ao estudante em casa e interação pais-escola"

Essa utilidade, já experimentada na rede mundial de computadores, promoverá mais uma vez a oportunidade de favorecer de várias maneiras o domínio do conhecimento de forma mais rápida e eficiente do que aquela possível com o audiovisual convencional ou de suporte apenas impresso.

É bem conhecido o papel fundamental do envolvimento pessoal do aluno no processo de aprendizagem. Quanto mais ativamente uma pessoa participar da aquisição de um conhecimento, mais ele irá integrar e reter aquilo que aprender. Ora, a multimídia interativa, graças à sua dimensão reticular e não-linear, favorece uma atitude exploratória, ou mesmo lúdica, em face do material a ser assimilado. É, portanto, um instrumento bem adaptado a uma pedagogia ativa ${ }^{10}$.

9. AMARAL, Sérgio Ferreira do; PACATA, Daniel Moutinho. A TV Digital Interativa no espaço educacional. Jornal da Unicamp, edição 229,15 a 21 set. 2003 .

10. LÉVY, op. cit., p. 40.
O presente texto traz um breve compêndio das potenciais formas de utilização e aproveitamento da televisão digital em contextos de aprendizado e ensino, como proposta de acoplar ao âmbito do debate técnico, já há algum tempo em desenvolvimento, uma discussão de caráter social quanto ao enfoque educativo do modelo, empenho expresso nos documentos oficiais do governo. 
A grande discussão no lançamento do novo sistema de televisão aportado numa tecnologia inovadora e bastante recente traz consigo o debate sobre a disputa em torno da ocupação do espectro de banda existente para o oferecimento dos programas, estes agora vistos na perspectiva de uma convergência cada vez mais intensa de produtos e serviços que poderão alavancar negócios específicos bastante significativos.

Fica evidente que, pela grandeza dos investimentos despendidos tanto por parte das iniciativas privadas como aqueles fomentados pelo governo, e apesar dos protestos das entidades contrárias à decisão, a nova televisão será mesmo predominantemente comercial e deverá atender às lógicas de mercado do sistema capitalista prevalecente. Isso significa que, sem o investimento dos grupos econômicos potentes, e aí podemos entendê-los tanto como a indústria de eletrônica quanto as empresas de telecomunicações com respaldo financeiro, não teremos uma televisão digital abrangente, principalmente se dependermos apenas das iniciativas estatais para o seu desenvolvimento.

Ainda assim, há possibilidade de ampliação das vozes nesse contexto específico, caso o governo aponte para uma regulamentação que permita a inserção de grupos economicamente menos privilegiados na exploração desse meio. Sabe-se, por exemplo, que o novo sistema ampliará em cerca de dez vezes a oferta de canais. Basta, portanto - e isso é considerável se comparado à situação da ocupação dos espaços televisivos observada no presente -, admitir que comunidades e grupos sociais não voltados aos interesses mercantilistas realmente ocupem seus nichos, pressupondo que eles existirão no novo sistema. Em um modelo ideal, dar lugar, inclusive, para que pequenos grupos produzam e divulguem seus próprios conteúdos televisivos, uma possibilidade propícia ao sistema de conexão em rede, como já experimentado pela internet.

A TV digital abre as portas, de uma maneira muito especial, para a alfabetização audiovisual permanente, possibilitando e fomentando nos espectadores a capacidade de produzir e analisar suas próprias mensagens [...] propiciando uma educação que promova uma intervenção social e coletiva crítica imprescindível para uma formação de cidadania ${ }^{11}$.

A primeira possibilidade de utilização cultural e educativa de um sistema digital de televisão seria a natural e apropriada migração das emissoras preexistentes ao novo modelo, com a incorporação dos recursos que estarão disponíveis e todas as inovações decorrentes. Essa migração é ensaiada já há algum tempo pelas grandes emissoras, desde quando iniciaram a substituição dos seus equipamentos analógicos por aparatos digitais de captura, tratamento e distribuição dos conteúdos.

Poderemos ter uma revolução na forma de assistir à televisão quando, por exemplo, o modelo de canais for substituído pela composição de uma grade individualizada de programação montada pelo usuário, uma evolução dos Eletronic Programme Guides ${ }^{12}$, que apresentam a programação organizada numa linha de tempo, já comuns em sistemas de TV a cabo e via satélite (por assinatura). A oportunidade de manipulação dessa grade de programação será viabilizada pela
11. AMARAL; PACATA, op. cit.

12. GAWLINSKI, Mark. Interactive television production. (Produção da televisão interativa). Oxford: Focal Press, 2003. p. 7 
comunicação \& educação • Ano XI • Número 3 • set/dez 2006

forma como os programas poderão ser buscados e recuperados pelo aparelho conectado ao sistema, e acessados no horário definido pelo usuário.

Além desse recurso, Gawlinski ${ }^{13}$ ainda apresenta outras possibilidades típicas do sistema digital de televisão que, já experimentadas em emissoras pelo mundo, certamente poderão ser consideradas como serviços inovadores se adotados no modelo brasileiro. São eles:

Teletext-style Services, pelo qual o usuário tem acesso a uma gama de informações e serviços de um dado canal (emissora), que deixaria de apenas transmitir programas para se transformar numa central informativa de serviços e entretenimento.

Os Walled Gardens são composições de serviços interativos especialmente preparados para a televisão digital, tendo em vista a utilização comercial do sistema. Será a aplicação mais promissora, pois permitirá o acesso a dispositivos para a aquisição instantânea de produtos ou serviços por meio de uma transação comercial via televisão. A qualquer momento, ao passar pelos programas, o telespectador irá encontrar formas de acesso a menus com termos como compra ou serviços, a partir dos quais poderá acessar shoppings virtuais para adquirir um produto.

A Internet on Television poderá fazer a ponte de acesso da televisão digital com a rede mundial de computadores, com base em conteúdos específicos que terão de estar adequados para a navegação no ambiente televisivo. O recurso tornará possível acessar serviços já consagrados na rede, como a visualização de e-mails ou dispositivos de comunicação instantânea. Sabe-se, porém, que a postura do usuário diante da televisão em nada se assemelha ao seu comportamento ante um microcomputador. A migração da internet para a televisão é, portanto, muito discutida e esbarra nos aspectos da adequação dessas interfaces e nas características específicas de uso de cada um dos aparatos que acessam a rede mundial de computadores.

Enhanced Television é o nome dado por Gawlinski ${ }^{14}$ às possibilidades de intervenção imediata do telespectador no conteúdo de um programa. Servirá para a manifestação de sinais de aceitação ou de recusa da audiência, por meio de enquetes instantâneas, votações ou amostragens da receptividade de determinado conteúdo. Ao passar pelo canal, o usuário poderá consultar um gráfico da receptividade do programa gerado pela manifestação de outros telespectadores, permitindo à emissora redefinir a sua condução e modificar o enfoque ou mesmo a profundidade da abordagem daquela exibição.

O Video-on-demand and Near-video-on-demand é um recurso de acesso a conteúdos disponíveis em um repositório, que poderá ser a própria emissora ou provedores específicos, para que o usuário os recupere conforme seu interesse, necessidade e tempo. Pode ser combinado com a elaboração personalizada do guia de conteúdo, mencionada anteriormente. Os repositórios serão uma forma de acesso a conteúdos que certamente irão contribuir com o contexto educativo, como será visto depois.

Personal Video Recorders é o nome do sistema que permite o congelamento

13. Ibid., p. 6-26

14. Ibid., p. 17. (pausa) e posterior retomada de um conteúdo televisivo, mesmo quando exibido pela primeira vez ou em transmissões ao vivo. O dispositivo simplesmente grava 
o programa em uma memória local, a partir do ponto em que é acionado. A capacidade de armazenamento depende do hardware utilizado. Outra funcionalidade permite que se grave uma programação enquanto se assiste a outra, e passe a exibi-la quando for conveniente.

Esses recursos poderão ou não ser adotados no Sistema Brasileiro de Televisão Digital Interativa, ou ainda ser incorporados conforme a capacidade de sua absorção pelos usuários e a viabilização econômica por parte das emissoras e provedores dos conteúdos e serviços. A sua utilização no contexto educacional, entretanto, está relacionada com a programação de cada emissora. Isso quer dizer que um canal poderá aplicá-los com fins puramente mercadológicos e de consumo, enquanto outro, de natureza educativa, usá-los tendo em vista um maior aproveitamento daquele conteúdo pelo usuário na construção e manipulação do conhecimento.

Espera-se, portanto, que a migração das emissoras preexistentes ao novo modelo preveja a utilização desses recursos apresentados por Gawlinski e de outros que certamente estarão disponíveis. Podemos prospectar que as emissoras educativas irão propiciar ao telespectador formas de acesso a programas culturais interativos e de entretenimento educativo numa perspectiva de utilização da televisão como aparato para uma efetiva promoção social em um novo contexto inclusivo.

$\mathrm{Na}$ perspectiva dos repositórios de programas, temos as próprias emissoras e provedores como atores principais da promoção desses novos usos para os conteúdos televisivos, a partir dos recursos típicos da televisão digital apresentados anteriormente neste texto. Um acervo fílmico com certeza pode contribuir com o acesso ao conhecimento, se forem facilitadas as formas de recuperação desses conteúdos. Ainda assim, vemos também na migração ao sistema digital de televisão das emissoras de caráter explicitamente educativo, como as televisões universitárias, por exemplo, uma forma real de multiplicação desses usos.

A Associação Brasileira de Televisão Universitária - ABTU ${ }^{15}$, por exemplo, articula, desde 2003, a criação da Rede de Intercâmbio de Televisão Universitária - RITU, para a difusão dos programas de televisão produzidos pelos associados e para que sirva de apoio à programação e distribuição dos canais educativos ou comunitários em operação no Brasil. O presidente da ABTU, Gabriel Priolli, em maio de 2005 apostava na "garantia de que haverá espaço [na TV digital] para os canais universitários que hoje estão limitados à TV a cabo"16, e confirmou o empenho da entidade para que os canais adicionais do sistema digital de televisão sejam ocupados por emissoras universitárias e não-comerciais, de interesse público, como os canais comunitários, legislativos institucionais e os educativo-culturais.

Uma rede de intercâmbio e difusão dos programas das televisões universitárias e outras emissoras apontadas pelo presidente da ABTU é perfeitamente plausível para o sistema digital de televisão, uma vez que resolve tecnicamente a questão do encapsulamento, envio e recepção dos conteúdos audiovisuais produzidos, funcionando como repositório acessível para a recuperação desses conteúdos.
15. <http://www.abtu.org $\mathrm{br} / \mathrm{ritu} / \mathrm{rituHome.asp}>$.

16. <http://www.abtu org.br/arquivos_tv_digital.asp>. Acesso em: 9 maio 2005. 
17. BASTOS, Alessandra TV digital revolucionará a escola pública brasileira. Agência Brasil - Centro de Imprensa. Disponivel em: <http:// www.radiobras.gov.br/ centro\%20imprensa/tv digital_231203/mat tvdigital2.php>. Acesso em: 23 dez. 2003.

18. PINTO, J. C.; NOVAES, T. O.; BONADIA, G. C. Serviço de Apoio ao Professor em Sala de Aula - SAPSA. Campinas: CPqD/Funttel, 2004.
Um outro exemplo da possibilidade de acesso aos repositórios de conteúdos tem sido testado desde dezembro de 2003, com a implementação da TV Escola Digital Interativa pelo Ministério da Educação, junto com a Secretaria de Educação a Distância. A iniciativa aconteceu muito antes da definição do padrão brasileiro e uma aparente desarticulação com o processo decisório do modelo de televisão digital do governo certamente tem gerado problemas e talvez explique as críticas que o sistema vem colecionando.

Trata-se do primeiro sistema de televisão digital interativa do País de uso exclusivo voltado à educação. O projeto é uma expansão da TV Escola, que atende a cerca de 42 mil escolas equipadas com televisor, videocassete, antena parabólica e receptor.

O sistema original analógico permitia apenas a gravação dos programas de televisão, recebidos via satélite, em fita de vídeo, para posterior aproveitamento ou exibição. O novo sistema possibilita ao educador o acesso a uma variedade de informações e serviços que são gravados na memória do mesmo aparelho que recebe o sinal, em um disco rígido (HD). Os dados ficam armazenados por até sete dias, mas podem ser gravados em CD e executados no próprio sistema, em computadores ou em reprodutores de DVD.

O sistema também oferece o recurso do canal de retorno, que permite alguma interatividade pela televisão digital: dá liberdade ao usuário para interagir não somente com o sistema, mas até enviar dados para os provedores de conteúdo. Diferentemente do sistema original analógico, a TV Escola Digital Interativa possibilita a transmissão de conteúdos complementares, como guias didáticos e de orientação, tabelas e questionários que poderão ser enviados de volta ao provedor do conteúdo, ou para a central de serviços prevista para ser instalada na Secretaria de Educação a Distância.

O programa do governo quer implementar o novo sistema digital em todas as 180 mil escolas do Ensino Básico no Brasil em quatro anos, um desafio se for considerado que o sistema analógico, implantado em março de 1996, atingiu menos que 50 mil estabelecimentos no país até $2003^{17}$. Na fase inicial, a TV Escola Digital Interativa abrangia 18 escolas e sete unidades espalhadas pelo Brasil que oferecem acesso informatizado à comunidade.

Partindo da possibilidade de uso da televisão digital nesse contexto específico de ensino, em sala de aula, o CPqD também elaborou uma proposta de sistema para o apoio aos professores baseada na TV digital interativa para ser usada no modelo escolhido, o Serviço de Apoio ao Professor em Sala de Aula - SAPSA ${ }^{18}$. O sistema prevê a interação entre os alunos e um repositório de conteúdo multimídia didático, com a mediação do professor, e pretende atender aos diferentes tipos de escola em diversos contextos sociais e geográficos do País.

$\mathrm{O}$ primeiro tipo de escola atendida é aquele estabelecimento pequeno e que está geograficamente isolado ou afastado, em áreas rurais e em municípios cobertos por sinais de televisão terrestre, mas que não têm acesso a uma rede de telecomunicações. Não terá canal de retorno e a requisição dos conteúdos será feita pelo serviço de correios. 
O segundo tipo de escola se caracteriza pelo acesso a um canal de retorno convencional, via telefonia fixa, utilizado para a requisição de conteúdos adicionais ao repositório. O terceiro tipo está localizado em regiões urbanas com acesso a canais eficientes de retorno (banda larga ou fibra ótica) e tem possibilidade de não apenas adquirir conteúdos (download), mas até mesmo de enviar uma eventual produção local para o repositório (up-load), disponibilizando-a aos demais grupos de ensino.

$\mathrm{O}$ último ponto a ser apresentado, proposto na pesquisa deste artigo, diz respeito a um exemplo de aplicação específica de conteúdo digital interativo que poderá ser utilizado no meio televisivo em questão e tem relação com as formas de educação informais ou com a formação continuada do aprendente. O Documentário Digital Interativo é uma prospecção sobre a apropriação das possibilidades técnico-operacionais da televisão digital interativa pelo gênero documentário, consagrado como produto fílmico, a partir de uma lógica estruturada pelas roteirizações em suportes multimídias ${ }^{19}$.

A partir dos estudos de Gosciola ${ }^{20}$, sobre como pensar os roteiros nas hipermídias, e da evolução do gênero documentário, vinculada à modernização dos aparatos tecnológicos, propõe-se reorganizar seu conteúdo, de forma a prever e incorporar em sua estrutura as informações e possibilidades extrafilme, que certamente serão aproveitadas em meios digitais que potencializam as utilizações dos recursos multimídias.

A nova modalidade [de documentário] herdará do cinema a leitura linear, embora possibilite, também, interrupções para o acesso a outras informações - multimídias -, com características de uma linguagem hipertextual e interativa, agregando as possibilidades da não-linearidade e multilinearidade. Além disso, os dados de retorno poderão ser direcionados ao provedor do conteúdo, conferindo ao documentário uma possibilidade didático-pedagógica nunca antes experimentada pelo gênero ${ }^{21}$.

Esse recurso de fruição do documentário numa televisão digital, por exemplo, vai depender do empenho e da transformação do olhar do produtor na incorporação, ao roteiro e ao conteúdo, de novos dados (extras, textos, fichas técnicas, interações educativas etc.) que tenham caráter de aprofundamento do assunto apresentado no filme e contribuam na consolidação das novas formas de acesso, construção e transformação do conhecimento.

\section{CONSIDERAÇÕES FINAIS}

A decisão oficial do governo sobre o modelo tecnológico para a TV digital no País marcou um caminho sem volta de transformação da televisão aberta no Brasil, principalmente enquanto possibilidade de inclusão social e uso cultural-educativo; e isso apesar das opiniões não muito positivas sobre a escolha do sistema japonês repercutidas nas organizações de cunho social que discutem o assunto.

O debate, amplo e profundo, poderá reverter-se em algum benefício efetivo caso seus pontos sejam considerados em uma nova regulamentação que deverá
19. SACRINI, Marcelo. Perspectivas do gênero documentário pela apropriação de elementos de linguagem da TV Digital Interativa. Campinas, SP: ETD - Educação Temática Digital, v. 5, n. 2, p. 7-22, 2004.

20. GOSCIOLA, Vicente. Roteiro para as novas mídias: do game à TV interativa. São Paulo: Editora Senac, 2003.

21. SACRINI, op. cit. 
surgir, imprescindível à modernização das comunicações no País ante as transformações tecnológicas ocorridas recentemente, e cada vez mais incisivas.

Partimos, neste estudo, das informações existentes e expressas em documentos e pesquisas desenvolvidas sobre a real aplicabilidade dos novos recursos televisivos no contexto apenas informal dos processos educativos. Foram apresentadas algumas possibilidades potenciais de uso cultural e de acesso ao conhecimento da ferramenta, sem ainda abordar os usos didáticos específicos, pesquisa esta que deverá ser posteriormente desenvolvida. Mesmo assim, já se vislumbra indícios de uma apropriação positiva dos recursos pelas emissoras e potenciais provedores de conteúdos. Uma eventual ampliação do número de canais com a chance da ocupação desse espaço pelas emissoras oficiais, comunitárias, educativas ou redes de intercâmbio de conteúdos educativos é uma oportunidade que não pode ser desconsiderada pelos interessados na promoção social deste País.

Almeja-se, ainda, que se possa apostar um dia na utilização plena dos recursos de uma TV digital como nó hipertextual de uma grande rede de conteúdos televisivos. Somente nesse caso irá se dar espaço e voz para grupos e indivíduos que passariam a produzir seus próprios conteúdos que, disponíveis a outros grupos, promoveriam uma visão muito mais crítica sobre esta sociedade que tem no audiovisual sua principal fonte de consumo, entretenimento e, por que não, de acesso ao conhecimento.

Resumo: O artigo traz uma reflexão sobre as expectativas geradas quanto à utilização cultural e educativa da televisão digital interativa após sua implementação e a apropriação de seus recursos pelos usuários e geradores dos conteúdos. Apresenta algumas possibilidades para o contexto cultural e educativo, os padrões tecnológicos concorrentes ao modelo definido e o movimento oficial na escolha do sistema brasileiro. A partir de uma pesquisa documental, o texto agrupa informações sobre a migração das emissoras ao sistema digital, sua utilização enquanto repositório de programas e rede de intercâmbio, a TV Escola Digital Interativa, Serviço de Apoio ao Professor em Sala de Aula e Documentário Digital Interativo.

Palavras-chave: televisão digital, educação e tecnologia, TV digital interativa.
Abstract: This article analyses the expectations related to the cultural and educative use of the interactive digital television after its implementation and appropriation of its resources for the users and generators of contents. It presents some possibilities for cultural and educative contexts, technological standards offered in comparison to the chosen one, and the official movement in the Brazilian system choice. From a documentary research, this study joins information on the migration of the senders to the digital system, its use as repository of programs and net of interchange, Interactive Digital School TV, Service of Support to the Professor in Classroom and Interactive Digital Documentary.

Keywords: digital television, education and technology, interactive digital TV. 